UJMR, Volume 5 Number 2, December, 2020, pp106 - 110 ISSN: 2616 - 0668 https://doi.org/10.47430/ujmr.2052.014

Received: $27^{\text {th }}$ November, $2020 \quad$ Accepted: $28^{\text {th }}$ November, 2020

\title{
Occurrence and Antimicrobial Susceptibility Profile of Coagulase Negative Staphylococci Isolated From Local Yoghurt Hawked in Gombe Metropolis, Nigeria
}

\author{
${ }^{* 1}$ Hamza, A.J., ${ }^{2}$ Onaolopo, J.A., ${ }^{2}$ Bolaji, R.O. and ${ }^{3}$ Ibrahim I.H. \\ 1 Department of Pharmaceutical Microbiology and Biotechnology, Gombe State University \\ ${ }^{2}$ Department of Pharmaceutical Microbiology, Ahmadu Bello University Zaria, Nigeria. \\ ${ }^{3}$ Department of Microbiology, Gombe State University \\ ${ }^{*}$ Correspondence to: Hamza Adamu Jabir, Department Pharmaceutical Microbiology and \\ Biotechnology, Gombe State University. \\ Email: jabirgsu@gmail.com; +2347039306208
}

\begin{abstract}
Coagulase-negative staphylococci (CoNS) were formally believed to be non-pathogenic but recent studies have implicated them as agents of some diseases. This study was designed to investigate the occurrence and antimicrobial susceptibility profile of CoNS isolated from local yoghurt hawked in Gombe metropolis, Nigerian. A total of 177 local yoghurt samples from Gombe metropolis were investigated for the presence of CoNS using standard microbiological methods and confirm using Microgen Staph ID kit. The antibiotics susceptibility profile of the confirmed isolates was determined using disc diffusion method. Out of the 177 yoghurt samples, a total $24(13.56 \%)$ were identified as CoNS which include: S. chromogenes $11(45.83 \%)$, S. haemolyticus 5(20.83), S. hominis $3(12.50 \%)$, S. warneri $3(12.50 \%)$, S. cohnis $1(4.17 \%)$ and S. ciuri $1(4.17 \%)$. Antimicrobial susceptibility testing revealed that the isolates were highly resistant to ampicilin (75\%) and cefoxitin (54.2\%) but very sensitive to gentamicin (100\%), vancomycin (95\%) and chloramphenicol (100\%). The study reveals the presence of CoNS in the study area that are highly resistant to conventional antibiotics. Thus, to ensure public health safety and to avoid transmission of drug resistant bacteria, there is the need to educate yoghurt producers, vendors and consumers on the importance of food safety by the relevant authorities.
\end{abstract}

Keywords: Coagulase negative staphylococci, Local yoghurt, Antimicrobial Resistance.

\section{INTRODUCTION}

Local yoghurt also known as Kindirmo is among the various type of fermented food produced from animal products in Nigeria (Patience et al., 2016). The process of its production is mainly fermentation and involve; collection of the fresh milk from the cow's udder into a clean container, allowing it to settle under the sun, followed by boiling, cooling, inoculating the milk with a starter culture and incubating it overnight for the fermentation to take place (Egwaikhide et al., 2014). The production of this yoghurt in Nigeria takes place in herds and villages and usually in small scale by women of Fulani tribe (Igwe and Yakubu, 2000).

Kindirmo is greatly patronize in most cities of the Northern Nigeria being part of the staple diet. However numerous studies including those by Robert et al., (2009) opined that consumption of such locally produced milk poses significant health burden in the society with increased morbidity and mortality as the milk may become contaminated with various organisms including those with multiple resistance to antibiotics in the process of production and distribution.
Antibacterial resistance is the ability of a bacteria to resist treatment with an antibiotic originally used in its treatment and it involves bacteria that cause many common to life threatening infections as there are available literature showing that much of the problem of infectious diseases worldwide result from antimicrobial-resistant bacteria and more virulent strains of such pathogenic microbes have evolved (Erb and Sturmer, 2007; Stevens and $\mathrm{Ma}, 2007$ ).

Coagulase negative staphylococci (CoNS) are important pathogens with food safety implications as they may contaminate food of animal origin including milk (Osman et al., 2016). Coagulase negative staphylococci are frequently isolated from bulk tank milk (Huber et al., 2011). Coagulase negative staphylococci may also be a reservoir of different staphylococcal enterotoxins genes causing food poisoning (Rodríguez et al., 2016). In addition, they may be a reservoir for multiple antimicrobial resistant genes (Szczuka et al., 2016). 
UJMR, Volume 5 Number 2, December, 2020, pp106 - $110 \quad$ ISSN: 2616 - 0668

Coagulase negative staphylococci (CoNS) which are known to be commensals on the skin of man and animals could be introduced into food when food producers lack personal hygiene and/or there is no quality control check during food processing or production (Klibiet et al., 2018). Coagulase negative staphylococci were long considered non-pathogenic and having few virulence factors however, this notion has been corrected as many studies have shown that just like the known pathogenic S. aureus, they also possess virulent factors and have been indicated as pathogens of diverse diseases (Akinkunmi and Lamikanra, 2012). CoNS have been recognized as etiologic agents of a wide variety of infections ranging from wound and urinary tract infection, neonatal sepsis, central nervous shunt, endocarditis etc (Patience et al., 2016).

The presence of CoNS in any food could therefore raise questions about its safety for human consumption. The aim of the study was to investigate the occurrence and antibiotic susceptibility profile of CoNS isolated from local yoghurt hawked in Gombe metropolis, Nigeria.

\section{MATERIALS AND METHODS \\ Sample Collection}

One hundred and seventy seven (177) samples of locally fermented cow milk were collected aseptically using sterile universal bottles, from three markets in Gombe metropolis. The samples were labeled accordingly and transported in an ice pack to the Pharmaceutical Microbiology and Biotechnology Laboratory, Gombe State University for further investigation.

Isolation and Identification of Coagulase Negative Staphylococci

The collected samples were cultured on Mannitol Salt Agar (MSA) according to the method previously described by Onaolapo et al., (2017), after 24 hours of incubation colonies that appeared golden yellow in colour on MSA plates with yellow surrounding (an indicative of fermentation) were considered as Staphylococci. These colonies were then subcultured onto a MSA again to obtain pure cultures from which stock cultures were immediately prepared. Gram-staining of isolates was carried out as described by Cheesbrough (2008). A smear of each isolate was made on a slide, the smear was heat-fixed and stained with crystal violet, and then allowed to stand for 10-60 seconds, the stain was poured off and rinsed gently with water. The smear was then mixed with Lugol's iodine solution, decolorized with ethanol and was then counterstained with safranin. The stained slide was examined under an oil-immersion lens and the isolates that appeared as violet cocci predominantly clusters were selected to be staphylococci. These isolates were then subjected to catalase test by addition of $1 \mathrm{ml}$ of a $3 \%$ hydrogen peroxide solution on a 24 hour nutrient agar slope culture of the isolate. This was carried out for all the suspected staphylococci isolates and evolution of gas was noted, the isolates that produced the gas were considered to be staphylococci and the isolates that were catalase negative as streptococci Cheesbrough, (2008). To differentiate CoNS isolates from staphylococcus aureus, the isolates were then subjected to coagulase test by dropping a physiological saline on each end of a slide and a colony of the test organism was emulsified in each drop to make two separate thick suspensions. A drop of plasma was then added to one of the suspensions and mixed gently and the ability or inability to form a clumping within 10 seconds suggested staphylococcus aureus or CoNS respectively (Onaolapo et al., 2017). Microgen ${ }^{T M}$ staph ID was further used to identify CoNS to a specie level (Onaolapo et al., 2017).

\section{Antimicrobial Susceptibility Testing}

The susceptibility of the isolates was tested against 10 different antimicrobials using the modified disk diffusion method as described by the clinical laboratory standard institute (CLSI, 2015). One to three (1-3) colonies were suspended in sterile saline, and the turbidity of the bacterial suspension was adjusted to a 0.5 McFarland standard. The standardized bacterial suspension was spread over Mueller Hinton agar and allowed to dry. Antimicrobial coated discs (Oxoid, Hampshire, England) that are;

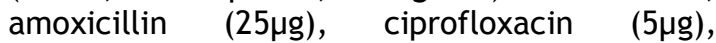
erythromycin $(15 \mu \mathrm{g})$, chloramphenicol $(30 \mu \mathrm{g})$,

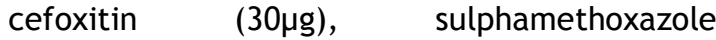
trimethoprim $(25 \mu \mathrm{g})$, doxycycline $(30 \mu \mathrm{g})$, amoxiclave $(30 \mu \mathrm{g})$, gentamicin $(10 \mu \mathrm{g})$ and vancomycin $(30 \mu \mathrm{g})$ were placed on the agar surface using an antibiotics dispenser, gently pressed with the aid of a sterile forceps to ensure complete contact with the agar surface. The plates were incubated aerobically at $37^{\circ} \mathrm{C}$ for $18 \mathrm{~h}$. Inhibition zone diameters $(\mathrm{mm})$ were measured in millimeters. The isolates were classified as resistant or susceptible to an antimicrobial based on the susceptible zone diameter $(\mathrm{mm})$. Isolates resistant to one or more antibiotics in three and more broad classes of antimicrobials in this study were recorded as multidrug-resistant (MDR) as described previously (Pesavento et al., 2007).

\section{RESULTS}

The result of the study revealed that 26 (14.69\%) and 24 (13.56\%) of the isolates were S. aureus and CoNS respectively (Table 1). 
UJMR, Volume 5 Number 2, December, 2020, pp106 - $110 \quad$ ISSN: 2616 - 0668

Table 1: Occurrence of Coagulase Negative Staphylococci among the study samples

\begin{tabular}{llccc}
\hline Number Examined & \multicolumn{2}{c}{ Staphylococcus } & aureus & \multicolumn{2}{c}{ Coagulase Negative Staphylococci } \\
\hline \multirow{3}{*}{177} & No. & $\%$ & No. & $\%$ \\
\hline
\end{tabular}

Table 2 revealed that among the three sampling sites, Tashan Dukku and Main Market had higher occurrence of CoNS of $15.25 \%$ each compared with Tashan Shango (13.56\%).

Similarly Tashan Dukku and Main Market had higher occurrence of $S$. aureus of $15.25 \%$ each compared with Tashan Shango (10.16\%) (Table 2).

Table 2: Distribution of Coagulase Negative Staphylococci (CoNS) and S. aureus among Three Markets of Gombe Metropolis

\begin{tabular}{lllll}
\hline Source & Sample size & $\begin{array}{l}\text { No./Percentage of } \\
\text { CoNS }\end{array}$ & $\begin{array}{l}\text { No./Percentage } \\
\text { of S. aureus }\end{array}$ \\
\hline 1 & Tashan Shango & 59 & $6(10.16 \%)$ & $8(13.56 \%)$ \\
2 & Tashan Dukku & 59 & $9(15.25 \%)$ & $9(15.25 \%)$ \\
3 & Main Market & 59 & $9(15.25 \%)$ & $9(15.25 \%)$ \\
Total & & 177 & $\mathbf{2 4 ( 1 3 . 5 6 \% )}$ & $\mathbf{2 6 ( 1 4 . 6 9 \% )}$ \\
\hline
\end{tabular}

Table 3 revealed that $S$. chromogenes and $S$. haemolyticus had the highest occurrence of 45.83\% and $20.83 \%$ among the isolated CoNS, while the least was S. cohnis $(4.17 \%)$ and $S$. ciuri $(4.17 \%)$. S. hominis and $S$. warneri had percentage occurrence of $12.50 \%$ each (Table 3). Additionally, among the three sampling sites, Main Market had the highest number of $S$. chromogenes isolates of 5 , followed by Tashan
Dukku (4) and Tashan Shango (2) (Table 3). Only one isolate of $\mathrm{S}$. cohnis was isolated from Tashan Shango and another one isolate of $S$. ciuri from Tashan Dukku (Table 3). Two isolates of $S$. haemolyticus were isolated each from Tashan Shango and Main Market, and one and two isolates of S. warneri from Tashan Shango and Main Market respectively (Table 3).

Table 3: Percentage Occurrence revalence of Coagulase Negative Staphylococci (CoNS)

\begin{tabular}{|c|c|c|c|c|c|c|}
\hline $\mathrm{S} / \mathrm{N}$ & CoNS & \multicolumn{3}{|c|}{ Distribution } & \multirow[t]{2}{*}{ Total } & \multirow[t]{2}{*}{ Percentage (\%) } \\
\hline & & $\bar{A}$ & B & $\mathrm{C}$ & & \\
\hline 1 & S. chromogenes & 2 & 4 & 5 & 11 & 45.83 \\
\hline 2 & S. haemolyticus & 2 & 1 & 2 & 5 & 20.83 \\
\hline 3 & S. hominis & 0 & 3 & 0 & 3 & 12.50 \\
\hline 4 & S. warneri & 1 & 0 & 2 & 3 & 12.50 \\
\hline 5 & S. cohnis & 1 & 0 & 0 & 1 & 4.17 \\
\hline \multirow[t]{2}{*}{6} & S. ciuri & 0 & 1 & 0 & 1 & 4.17 \\
\hline & Total & & & & 24 & \\
\hline
\end{tabular}

Key: A: Tashan Shango; B: Tashan Dukku; C: Main Market

The antibiotics susceptibility testing revealed that, the highest resistance of $75 \%(18 / 24)$ by the CoNs isolates was recorded against Ampicillin, followed by $54.2 \%$ against Cefoxitin and $33.3 \%$ each against Erythromycin and Trimethoprime/sulfamethaxazole (Table 4).
Table 4 also revealed that the most sensitive drugs were Gentamicin (100\%) and Chloroamphenicol (100\%). Followed by Vancomycin (98.5\%), Amoxiclave (83.3\%), Ciprofloxacin (83.3\%) and Doxycycline (75\%).

Table 4: Antibiotics Susceptibility Profile of Coagulase Negative Staphylococci Isolates

\begin{tabular}{llll}
\hline Antibiotics & Potency & \multicolumn{2}{c}{ Coagulase Negative Staphylococci (n=24) } \\
\cline { 2 - 4 } Ampicillin & & Sensitive & Resistant \\
Ciprofloxacin & $10 \mu \mathrm{g}$ & $6(25 \%)$ & $18(75 \%)$ \\
Erythromycin & $5 \mu \mathrm{g}$ & $20(83.3 \%)$ & $4(16.75)$ \\
Chloroamphenicol & $15 \mu \mathrm{g}$ & $16(66.7 \%)$ & $8(33.3 \%)$ \\
Cefoxitin & $30 \mu \mathrm{g}$ & $24(100 \%)$ & $0(0 \%)$ \\
Trimethoprim/sulfamethaxazole & $30 \mu \mathrm{g}$ & $11(45.8 \%)$ & $13(52.2 \%)$ \\
Doxycycline & $30 \mu \mathrm{g}$ & $16(66.7 \%)$ & $8(33.3 \%)$ \\
Amoxiclave & $30 \mu \mathrm{g}$ & $18(75 \%)$ & $6(25 \%)$ \\
Gentamicin & $10 \mu \mathrm{g}$ & $20(83.3 \%)$ & $4(16.7 \%)$ \\
Vancomycin & $30 \mu \mathrm{g}$ & $24(100 \%)$ & $0(0.00 \%)$ \\
\hline $\mathrm{n}=$ number of CoNS & $23(95.8 \%)$ & $1(4.2 \%)$ \\
UMYU Journal of Microbiology & Research & &
\end{tabular}


UJMR, Volume 5 Number 2, December, 2020, pp106 - $110 \quad$ ISSN: 2616 - 0668

DISCUSSION

The result obtained from the study established that the percentage occurrence of CoNS isolated from local yoghurt samples of the study area was $13.56 \%$. The occurrence of CoNS in the yoghurt samples might have a relation with the people preparing and serving the yoghurt since staphylococci are commensals of human body thus, they can be introduced into the yoghurt, or it could be from the cows that suffer from mastitis since the organisms are associated with the disease in cows. The result varied with the findings of Patience et al. (2016) who revealed a total of $79.3 \%$ CoNS in fermented food including Kindirmo, the difference observed between the two studies could be due to variation in sampling environment and sample size used in the studies.

In this study, the prevalence of CoNS varies in the three sample locations, relatively low in Tashan Shango than Tashan Dukku and Main Market; the difference may be because Tashan Shango is relatively less congested (with people) than the other markets, hence there is less tendency of contamination in the place.

Among the CoNS isolates identified in the study, S. chromogenes had the highest percentage of occurrence in the local yoghurt samples examined, this may be due to the frequent association of $\mathrm{S}$. chromogenes with mastitis in cows than other species (Egwaikhide et al., 2014).

The study findings reported high resistance of CoNS to Ampicillin followed by cefoxitin. High AMR to penicillin have also been reported among CoNS isolates from different animal samples; 94.2\%in China, $77.8 \%$ in Pakistan (Syed et al., 2018) and $70.6 \%$ in Tunisia (Klibiet et al., 2018). The reasons for the widespread AMR isolates in Nigeria may be due to overuse and

\section{REFERENCES}

Akinkunmi, E. O. and Lamikanra, A. (2012). Phenotypic determination of some virulence factors in staphylococci isolated from faecal samples of children in Ile-Ife, Nigeria. African Journal of biomedical research, 15:123-128.

Cheesbrough M. (2008). Laboratory Practice in tropical countries. Part II, Cambridge University Press, United Kingdom, part 2 pp.13.

Clinical and Laboratory standards Institutes (CLSI). (2015). Performance Standards for Disease, 2(2): 115-129.

Dilbaghi, N. and Sharma, S. (2007). Food infections and intoxications caused by microorganisms and methods for their detection. Corpus ID: 4650369 Available at:

UMYU Journal of Microbiology Research misuse of these antimicrobials (Yadesa et al., 2015; Gebretekle and Serbessa, 2016), abuse in veterinary medicine and unregulated movement (smuggling) of the antimicrobials (Suleman et al., 2016). The study also established that the CoNS isolates were completely sensitive to Chloroamphenicol and Gentamicin, followed closely by Vancomycin. The high performance of these antibiotics (chloramphenicol, vancomycin and gentamicin) against CoNS isolates could be due to their molecular sizes, a factor which enhances their solubility in diluents thus promoting their penetration power through cell wall into cytoplasm of the bacteria (Onaolapo et al., 2017). Moreso, all the three antibiotics are administered using injection and not orally, hence limiting the level of their misuse in human because it requires a service of a professional for their administration, consequently reducing the level of resistance against them.

\section{CONCLUSION}

The study revealed the presence of CoNS in local yoghurt vended at Gombe municipal area with a percentage occurrence of $13.56 \%$. The most common CoNS identified were $S$. chromogenes and S. haemolyticus. Most CoNS isolates were resistant to ampicillin, erythromycin and cefoxitin and were hundred percent susceptible to gentamicin and chloroamphenicol followed by vancomycin. The detection of CoNS and especially the demonstration of drug resistance in yoghurt which is being consumed widely as food not only in the study area but in Nigeria calls for the for public awareness on dangers associated with consumption of contaminated product and the various ways to avoid it by the relevant authorities.

http://nsdl.niscair.res.in/bitstream/12345 6789/386/2/FoodSpoilage.pdf, December 16,2020

Egwaikhide, P. A., Malu, P. S., Lawal, U., Adelagun, R. O. and Andrew, C. (2014). Physico- Chemical and Microbiological Analysis of Fermented Cow Milk (Nono) Consumed Within Kaduna Town, NorthWestern Nigeria. Food Science and Quality Management, 7(2):26-30.

Erb, A. and Sturmer, T. (2007). Prevalence of antibiotic resistance in Escherichia coli: Overview of geographical, temporal, and methodological variations. European Journal of Clinical Microbiology and Infectious Disease, 26 (2): 83-90.

Evans, C. E., Amanabo, M., Yahaya, A. and Bello, M. (2013). Nigerian Indigenous Fermented Foods: Processes and 
UJMR, Volume 5 Number 2, December, 2020, pp106 - $110 \quad$ ISSN: 2616 - 0668

Prospects. Mycotoxin and Food Safety in Developing Countries. Intechopen, Croatia. 1096.

Gebretekle, G.B. and Serbessa, M.K. (2016). Exploration of over the counter sales of antibiotics in community pharmacies of Addis Ababa, Ethiopia: pharmacy professionals' perspective. Antimicrobial Resistant and Infection Control 5, 2(2016).

Huber, H., Ziegler, D., Pflüger, V., Vogel, G., Zweifel, C. and Stephan, R. (2011). Prevalence and characteristics of methicillin-resistant coagulase-negative staphylococci from livestock, chicken carcasses, bulk tank milk, minced meat, and contact persons. BMC Veterinary Research, 7,6 (2011).

Igwe, E.C. and Yakubu, B. (2000). The Adamawa Dairy Industry: In: Agriculture in Adamawa State. Edited by Igwe, EC., Mishelia, S.I. and Jada, MY. Parclete Publishers, Yola, Nigeria. ISBN: 978-805526-51.

Klibiet, A., Maaroufi, A., Torres, C. and Jouini, A. (2018). Detection and characterization of methicillin-resistant and susceptible coagulase-negative staphylococci in milk from cows with clinical mastitis in Tunisia. International Journal of Antimicrobial Agents 52: 930-935.

Onaolapo, J.A., Igwe, J.C., Bolaji, R.O., Adeshina, G.O. and Parom, S.K. (2017). Antibiotics Susceptibility Profile of Staphylococcus aureus Isolated from Poultry Birds in Kaduna, Nigeria. Journal of Clinical Microbiology and Antimicrobiol, 1: 101.

Osman, K.M., Amer, A.M., Badr, J.M., Helmy, N.M., Elhelw, R.A., Orabi, A., Bakry, M. and Saad, A.S.A. (2016). Antimicrobial resistance, biofilm formation and mecA characterization of methicillinsusceptible $S$. aureus and non-S. aureus of beef meatorigin in Egypt. Frontiers in Microbiology, 7:222.

Patience, T., Fowoyo1 S. and Temitope O., (2016). Occurrence and Characterisation of Coagulase-Negative Staphylococci from Nigerian Traditional Fermented Foods. Food Science and Quality Management, 50: 2224-6088 .

Pesavento, G., Ducci, B., Comodo, N. and Nostro, A.L. (2007). Antimicrobial resistance profile of Staphylococcus aureus isolated from raw meat: a research for methicillin resistant Staphylococcus aureus (MRSA). Food Control, 18: 196-200

Roberts, R., Hota, B., Ahmad, I., Scott, R. D. and Foster, S. D. (2009). Hospital and societal costs of antimicrobial-resistant infections in a Chicago teaching hospital: implications for antibiotic stewardship. Clinical Infectious Disease, 49:1175-1178

Rodríguez, A., Gordillo, R., Andrade, M.J., Cordoba, J.J. and Rodríguez, M. (2016). Development of an efficient real-time PCR assay to quantify enterotoxin-producing staphylococci in meat products. Food Control 60: 302-308.

Stevens, D.L. and Ma, Y. (2007). Impact of antibiotics on expression of virulenceassociated exotoxin genes in methicillinsensitive and methicillin-resistant Staphylococcus aureus. Journal of Infectios Disease, 195 (2): 202-211.

Suleman, S., Woliyi, A., Woldemichael, K., Tushune, K., Duchateau, L., Degroote, A., Vancauwenberghe, R., Bracke, N. and Spiegeleer, B.D., (2016). Pharmaceutical regulatory framework in Ethiopia: a critical evaluation of its legal basis and implementation. Ethiopian Journal of Health Science, 26: 259-276

Supr, K., Haesebrouck, F., Zadoks, R.N., Vaneechoutte, M., Piepers, S. and De Vliegher, S. (2011). Some coagulasenegative staphylococcus species affect udder health more than others Journal of Dairy Science, 94, 2329-2340.

Syed, E., Satti, F.N., Mubasher, S., Rasheed, F., Ilyas, M., Anwar, A.I. and Zaman, W.U. (2018). Coagulase-negative staphylococcus species; resistance and therapeutic decisions at the turn of the novel millennium. Professional Medical Journal. 2:764-769

Szczuka, E., Jabłonska, L. and Kaznowski, A., (2016). Coagulase-negative staphylococci: pathogenesis, occurrence of antibiotic resistance genes and in vitro effects of antimicrobial agents on biofilm-growing bacteria. Journal of Medical Microbiology 65: 1405-1413

Taponen, S., Bj€orkroth, J. and Py€or€al€a, S. (2008). Coagulase-negative staphylococci isolated from bovine extramammary sites and intramammary infections in a single dairy herd.Journal Dairy Research, 75: 422-429

WHO, (2000): Ibrahim, M. K., Gala, A. M., AlTurk, I. M. and Al-Zhrany K. D. Antibiotic resistance in Gram-negative pathogenic bacteria in hospitals' drain in A-Madina AlMunnawara.JTUSCI, 3:14-22

Yadesa, T.M., Gudina, E.K., Angamo, M.T., (2015). Antimicrobial use-related problems and predictors among hospitalized medical in-patients in Southwest Ethiopia: prospective observational study. PloS One 10(12): e0138385. 